\title{
I AM THE BOY WITH ONE HAND WHO CAN DO ANYTHING": PERCEPTIONS OF ABILITY AMONG PEOPLE WITH UPPER LIMB ABSENCE
}

\author{
Cody L. McDonald ${ }^{1 *}$, Cynthia L. Bennett ${ }^{1}$, Daniela K. Rosner ${ }^{1}$, Katherine M. Steele ${ }^{1}$ \\ ${ }^{1}$ University of Washington, USA. \\ *Email: codym@uw.edu
}

DOI: https://doi.org/10.33137/cpoj.v1i2.32001

\section{INTRODUCTION}

Upper limb prostheses are commonly prescribed for people with upper limb absence (ULA) to restore function, cosmesis, and assist with activities of daily living. However, nearly one in five people with ULA chooses not to use a prosthesis ${ }^{1}$ and instead turns to alternative technology and adaptations, pointing to factors beyond prostheses that shape perceptions of ability and quality of life. We examined through interviews the lived experiences of people with ULA framed around their perceptions of ability, device use, and quality of life.

\section{METHODS}

Sample: Convenience sample of individuals with ULA. Eligibility criteria: 18 years of age or older with ULA. Study design: Qualitative semi-structured interviews. Procedures: Semi-structured interviews were conducted with individuals with ULA. Participants also completed three surveys: Orthotics and Prosthetics Users' Survey (OPUS)- Upper Extremity, OPUS Health Quality of Life Index, ${ }^{2}$ and Amputee Body Image Scale. ${ }^{3}$

Analysis: A team of five multidisciplinary researchers (a prosthetist, three designers, and a mechanical engineer) used an interpretive phenomenological analysis to identify common themes. Two researchers coded each interview. Open codes were then distilled into central themes through reduction. Transcripts were then reviewed to identify final themes and representative text.

\section{RESULTS}

Fourteen participants with ULA, aged 18-71 years (mean age: $41.4 \pm 19$ years, 7 males $/ 7$ females) participated in this research. Most participants had congenital limb absence (10/14) of the distal limb (5 partial hand, 1 wrist disarticulation, and 5 transradial). Six participants reported daily use of a prosthesis; all participants had prior experience with at least one type of conventional ULP (i.e., passive, body-powered, or myoelectric). Five participants had also received e-NABLE 3D-printed devices, but no longer used them.
Survey: Participants reported high functional ability during tasks of daily living $(109.5 \pm 2.6)$. Individuals with congenital limb absence reported higher function $(116.3 \pm 18.7)$ compared to those with acquired ULA $(94.3 \pm 23)$, which may reflect the influence of time since limb loss and learning.

Themes: Participants shared high perceptions of ability and function, regardless of prosthesis or assistive technology use (Table 1). Life experiences related to three dimensions strongly influenced perceptions of ability:

- Learning to live with limb absence

- Integrating limb absence into individual identity

- Fostering supportive communities.

The diversity of experiences across participants highlighted the limitations of identifying "normative" pathways of recovery or device use, emphasizing the need for flexible and adaptable systems to creatively support personal goals and needs.

Table 1: Qualitative themes and representative quotes.

\begin{tabular}{|c|c|}
\hline Theme & Representative quote \\
\hline Ability & $\begin{array}{c}\text { "I just need to find my own ways... I } \\
\text { never believed that I couldn't do it. } \\
\text { It's 'how' I should do it, but not 'can' } \\
\text { I do this."-Brian, partial hand }\end{array}$ \\
\hline Learning & $\begin{array}{c}\text { "I felt like I had to work a little harder } \\
\text { and I'm determined because I'm not } \\
\text { going to let something like that get in } \\
\text { my way." - Julie, transradial }\end{array}$ \\
\hline Identity & $\begin{array}{c}\text { "It's an assistive device, but it's more } \\
\text { than that. It becomes part of you } \\
\text { through frequent use."-Elizabeth, } \\
\text { transradial }\end{array}$ \\
\hline Community & $\begin{array}{c}\text { "I even went to an amputee camp and } \\
\text { that really helped a lot....having so } \\
\text { many other people that were going } \\
\text { through the same thing and kind of } \\
\text { having a week of not caring about it." } \\
\text {-Taylor, transhumeral }\end{array}$ \\
\hline
\end{tabular}




\section{CONCLUSION}

Integration of novel platforms for professional practice, supportive communities, and technology innovation can support the evolving needs and care of people with ULA.

\section{REFERENCES}

1. Biddiss EA, Chau TT. Upper limb prosthesis use and abandonment: a survey of the last 25 years. Prosthet. Orthot. Int.2007; 31, 236-257. DOI: 10.1080/03093640600994581

2. Heinemann, AW. Bode RK, O'Reilly C. Development and measurement properties of the Orthotics and Prosthetics Users' Survey (OPUS): a comprehensive set of clinical outcome instruments. Prosthet. Orthot. Int.; 27, 191-206 2003. DOI: 10.1080/03093640308726682

3. Gallagher P, et al. Body image in people with lower-limb amputation: a Rasch analysis of the Amputee Body Image Scale. Am. J. Phys. Med. Rehabil. 2007; 86, 205-215. DOI: 10.1097/PHM.0b013e3180321439

\section{ACKNOWLEGEMENTS}

This work was supported by the National Science Foundation, Grants No. CBET1452646,1453329, and 1423074. 